\title{
The Spatial and Temporal Change of Snow Days in Inner Mongolia in Recent 35 Years
}

\author{
Chenhao Li ${ }^{1,2,3}$, Chula Sa ${ }^{1,2,3}$, Guixiang Liu ${ }^{4}$, Mulan Wang ${ }^{1,2,3}$, Junde Hu${ }^{1}$ \\ ${ }^{1}$ College of Geographical Science Inner Mongolia Normal University, Hohhot 010022, China \\ ${ }^{2}$ Inner Mongolia key laboratory of remote sensing and geographic information system, College of \\ Geographical Science Inner Mongolia Normal University, Hohhot 010022, China \\ ${ }^{3}$ Inner Mongolia Key Laboratory of Disaster and Ecological Security on the Mongolia Plateau, \\ College of Geographical Science Inner Mongolia Normal University, Hohhot 010022, China \\ ${ }^{4}$ Grassland Research Institute of Chinese Academy of Agricultural Sciences, Hohhot 010011, China \section{李晨昊 ${ }^{1,2,3}$, 萨楚拉 ${ }^{1,2,3}$, 刘桂香 ${ }^{4}$, 王牧兰 ${ }^{1,2,3}$, 胡君德 ${ }^{1}$ \\ 1 内蒙古师范大学地理科学学院, 呼和浩特 010022 , 中国 \\ 2 内蒙古自治区遥感与地理信息系统重点实验室, 呼和浩特 010022 , 中国 \\ 3 内蒙古自治区蒙古高原灾害与生态安全重点实验室, 呼和浩特 010022 , 中国 \\ 4 中国农业科学院草原研究所, 呼和浩特 010011, 中国} \\ 近 35 年内蒙古地区积雪日数时空变化特征
}

\begin{abstract}
Snow cover days are an important parameter to characterize the variation of snow cover and it's also sensitive factors of regional climate response. This paper we used 1979-2014 older time series of microwave remote sensing data in Inner Mongolia and 47's weather station meteorological observation data analyzes the temporal and spatial variation characteristics of snow cover days of Inner Mongolia and its response to climate factors, results obtained from year 1979 to 2013, Inner Mongolia Plateau snow cover days were significantly decreased $(\mathrm{P}<0.01)$. Inner Mongolia snow cover days mutation was in 2001.Influenced
\end{abstract}

通讯作者: 萨楚拉（1977-）, 男, 博士, 副教授, 主要从事遥感与地理信息系统应 用研究。Email: sachulan@126.com。 by topography and water, Inner Mongolia snow cover days high values are distributed in the northeast of HulunBuir plateau and Greater Khingan Mountains, XilinGol northeast area and XilinGol in eastern and Chifeng City in western of the transition zone. Low value areas mainly distributed in the Western league and City, Baotou City, Bayan Nur City, Ordos City and Alxa league.

Keywords: Inner Mongolia; snow cover days; spatial and temporal variation; climate response

摘要

积雪日数是表征积雪变化的重要参 数, 也是区域气候响应的敏感因素。利用 1979 2014 年长时间序列的微波遥感数据和 内蒙古地区 47 个气象站台的气象观测数据 
分析了内蒙古积雪日数的时空变化特征及 其对气候因子的响应, 结果指出: 1979 2014 年内蒙古地区积雪日数呈显著增 长趋势 $(\mathrm{P}<0.01)$, 内蒙古积雪日数的突变 年份是 2001 年。受地形和水分的影响, 内 蒙古积雪日数高值均分布在东北部的呼伦 贝尔高原和大兴安岭, 锡林郭勒盟东北部 地区和锡林郭勒盟东部与赤峰市西部的交 接地带; 低值区主要分布在西部盟市, 包 头市-巴彦淖尔市-鄂尔多斯市-阿拉善盟一 线。

关键词: 内蒙古; 积雪日数; 时空变化; 气候响应

\section{1. 引言}

冰冻圈的是气候系统五大圈层之一, 在减少下垫面接收太阳短波辐射的同时, 也阻碍着下垫面与大气的热量交换, 且冰 雪融化引起的水文效应也会改变下垫面的 状况, 冰雪对气温的作用显著, 冰雪滞留 时间的长短影响了气温的高低 ${ }^{[1]}$ 。

目前, 研究积雪的资料包括地面观测 资料和卫星遥感资料两类, 地面观测资料 主要是气象站等观测的积雪量、积雪日数 和积雪深度资料 ${ }^{[2-3]}$ 。李培基等 ${ }^{[4]}$ 分析统计 了全国近 1600 个气象站台资料, 计算得出 了多年平均积雪日数的分布状况, 并绘制 了 1:400 万的地图。韦志刚等 ${ }^{[5]}$ 选取了青藏 高原 72 个站台逐日观测的积雪深度数据, 分析了青藏高原积雪的空间分布和年代际 分布特征, 得到青藏高原的积雪的年变程 并不完全一致且存在三个积雪高值中心。 卫星遥感类资料包括光学遥感观测的可见 光遥感资料和微波遥感资料。刘俊峰等 ${ }^{[6-7]}$ 结合 MODIS 的 Aqua 和 Terra积雪产品, 获 取了 2001 2006 年全国积雪日数分布, 对 比三大稳定区, 得出新疆积雪的稳定性及 连续性最好, 东北-内蒙古地区次之, 青藏 高原的稳定性最差。萨楚拉等 ${ }^{[8]}$ 利用 MODIS 积雪产品 (MOD10A2), 分析了内 蒙古积雪面积的时空分布特征及气候响 应, 得到了近 10 年内蒙古积雪面积年内变 化呈现单峰和双峰的波动特点, 且气温的 上升引起了暖冬化, 可能导致积雪面积的
减少。田柳茜等 ${ }^{[9]}$ 利用微波遥感数据 (SMMR、SSM/I、AMSRE), 分析了青藏 高原 1979 2007 年间积雪深度和积雪日数 的分布变化及其趋势, 青藏高原积雪在 1988 年发生突变, 且青藏高原北部积雪变 化与全国趋势相反呈极显著增加。

内蒙古地区积雪对内蒙古的畜牧业和 草原牧区草地畜牧业的平衡可持续发展 ${ }^{[10-12]}$ 早为人们所重视。据统计内蒙古 27 年 (1978 2004 年) 间共有 66 个旗县发生了 468 次不同程度的雪灾, 仅 2010 年的三起 特大雪灾, 全年受灾人数累计达 45.28 万, 受灾牲畜累计达 424.7 万头只, 直接经济损 失 8.01 亿元 ${ }^{[13]}$ 。卓义等 ${ }^{[14]}$ 指出冬季积雪覆 盖是影响火险程度的重要因子。因此准确 监测积雪的变化是草原牧区灾害, 特别是 雪灾评估和风险评价研究的基础, 是减轻 雪灾的重要支撑。同时, 积雪的变化会对 区域气候的变化产生影响, 有必要从时间 和空间搞清楚积雪自身的变化, 从而准确 判断积雪对气候因子变化的影响。

\section{2. 材料与方法}

\section{1 数据源及数据处理}

本文采用中国气象数据网提供的 1979 2014 年内蒙古地区 47 个气象站台的气象 观测数据(图 1)。

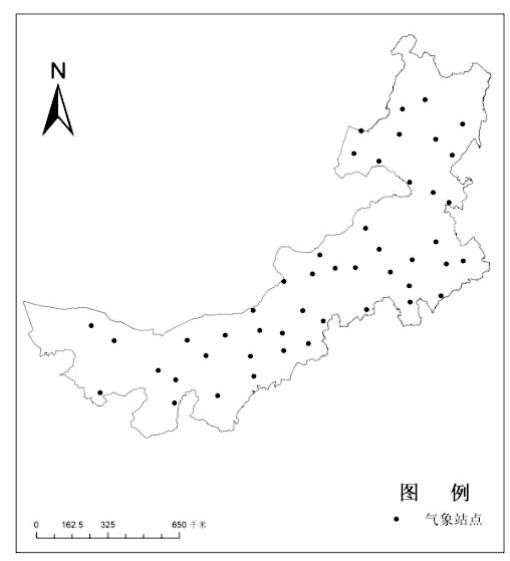

图 1 内蒙古地区气象站点分布图

本文采用 1979 2014 年中国雪深长时 间序列数据集提供 1979 年 1 月 1 日到 2014 
年 12 月 31 日逐日的中国范围的积雪厚度分 布数据。用于反演该雪深数据集的原始数 据来自美国国家雪冰数据中心（NSIDC） 处理的 SMMR(1979 1987 年), SSM/I(1987 2007 年)和 SSMI/S(2008 2014 年)逐日被动 微波亮温数据, 最后利用车涛在 Chang 算 法基础上针对中国地区进行修正的算法进 行雪深反演 ${ }^{[15]}$ 。

将雪深数据进一步处理提取积雪日数 数据。首先, 采用 ArcGIS 软件将原始雪深 数据转化成栅格数据并把雪深数据的投影 统一转换为 Albers 投影, 进而用内蒙古界 限裁剪生成空间分辨率为 $25 \mathrm{~km}$ 的内蒙古逐 日栅格雪深数据, 然后运用 ArcGIS 软件中 的 Raster to Point 模块提取内蒙地区的点数 据, 利用点专题数据在 ArcGIS 软件中的 Extract Multi Values to Point 模块提取每年积 雪季的雪深数据, 运用 $\mathrm{VC}++6.0$ 语言编程 实现按照积雪参数的定义来统计积雪季节 的积雪参数, 最后利用 ArcGIS 软件连接点 数据和统计的积雪参数的以及 Point to Raster 模块得到内蒙古的积雪日数的专题地 图。

本文将每年 10 12 月至翌年 1 3 月算 作当年的积雪日数。

本文以距平大于标准差 2 倍为异常, 大 于标准差 $1.5 \sim 2$ 倍为接近异常来判断内蒙古 地区积雪日数的异常特征。

\section{3. 结果与分析}

\section{1 内蒙古积雪日数时间变化}

\subsection{1 内蒙古积雪日数年际变化}

由于内蒙古地区每年受北部蒙古高原 和西伯利亚冷空气的影响程度不同, 积雪 日数所表现出的时间特性也有很大的差 异。

如图 2, 35 年来内蒙古地区年均积雪日 数维持在 31 82 天之间。积雪日数年际变 化最大相差 51 天, 平均值为 53 天, 标准差

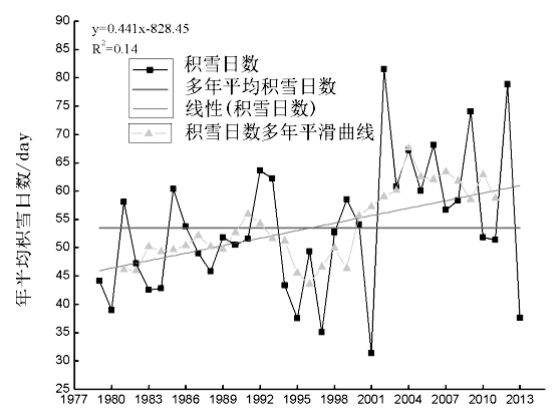

图 $21979^{\sim} 2013$ 年的年均积雪日数年际变化

为 12 天, 波动振幅很大。其线性变化表 明:

1979 2014 年内蒙古地区积雪日数呈显著 增长趋势, 气候倾斜率为 $4 / 10 \mathrm{a}$, 通过 $\mathrm{P}<0.05$ 的显著性检验。

由积雪日数五年平滑曲线可知, 内蒙 古积雪日数在 1996 年后积雪日数表现为明 显上升趋势, 波动振幅很大, 标准差为 12 天, 且 2000 年以后波动较小, 平滑的标准 差为 3 天。

\section{1 .2 内蒙古积雪突变分析}

由内蒙古 35 年的积雪日数累计距平 值, 结果发现年均雪深在 2001 年发生转 折, 累计距平值达到-105 天, 且信噪比达到 0.63。这很好的印证了前面积雪日数在进入 21 世纪增加的代际分布特点。

\subsection{3 内蒙古积雪异常值分析}

由表 1 可知, 内蒙古积雪日数异常偏多 发生在 21 世纪以后, 即 2002 年, 2009 年 和 2012 年, 较多年平均积雪日数分别偏多 28 天, 21 天和 25 天。积雪日数异常偏少值 在 20 世纪 90 年代只发生了一次, 即 1997 年, 较多年平均积雪日数少了 18.4 天; 21 世纪后发生一次, 即 2001 年, 较多年平均 积雪日数偏少 22 天。 2001 年积雪日数偏少 与 1997 年春季和 2001 夏季旱灾发生的时间 点保持一致, 导致积雪日数的缩减和水分

表 $1 \quad 1979^{\sim} 2014$ 年内蒙古地区积雪日数异常年份

\begin{tabular}{ccc}
\hline 时段 $($ 年) & 接近异常 & 异常 \\
\hline 积雪日数 & $1997(-) 2001(-) 2009(+)$ & $2002(+) 2012(+)$ \\
\hline
\end{tabular}


储备不足, 严重阻碍了内蒙古农牧业的发 展 $^{[16]}$ 。

\section{2 内蒙古积雪空间分析}

\subsection{1 内蒙古积雪空间变化}

由于内蒙古地域广, 东西跨度大, 且 各地所处纬度和海拔差异大, 使得内蒙古 地区积雪分布有明显的空间地域性特征 (图 3), 同时积雪的分布也受到地形因子 和气候因素的显著影响。呼伦贝尔市, 兴 安盟和锡林郭勒盟的多年平均积雪日数分 别为 129 天, 80 天和 60 天, 均多于研究区 平均积雪日数 (53 天), 其余盟市多年平均 积雪日数均低于平均积雪日数。积雪日数 的多少受地形和水汽输送的影响尤为明
显。

内蒙古积雪的空间分布与地形变化存 在一定的关系。海拔越高, 气温越低, 积 雪融化的速度延缓, 从而影响积雪滞留的 天数。内蒙古海拔最低点在东南部的西辽 河流域, 最高点在西部的贺兰山（图 $4(\mathrm{a})$ 。

将内蒙古地区的海拔按 104 200 米, 201 1000 米, 1001 1800 米, 1801 2600 米, 2601 3430 米分为五段 (图 4(b)), 统 计得到多年平均积雪天数分别为 25.2 天, 79.2 天, 42.2 天, 43.2 天, 10.3 天。积雪 日数受海拔的影响明显, 海拔在 200 米以上 雪深陡增, 1000 米以上又出现下降, 201 1000 米的海拔在内蒙古的分布很特 殊, 包括东部的呼伦贝尔市, 大兴安岭的

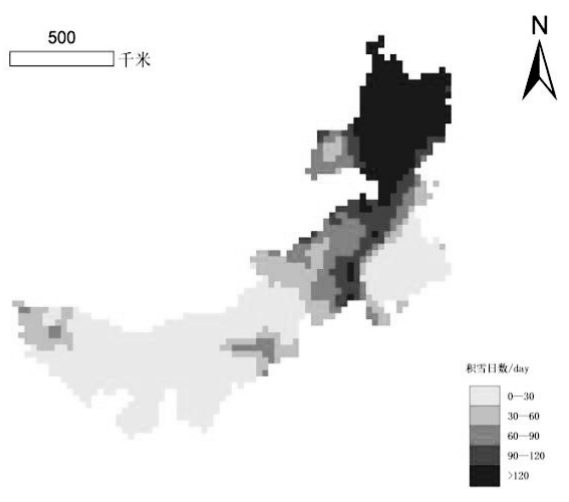

图 $31979^{\sim} 2013$ 年内蒙古地区年平均积雪日数分布图

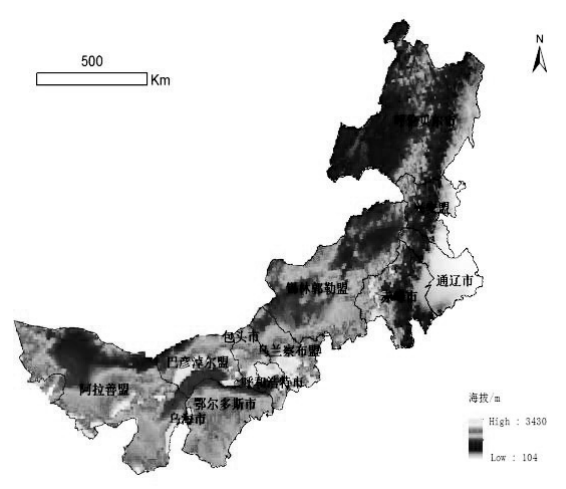

(a) DEM 图

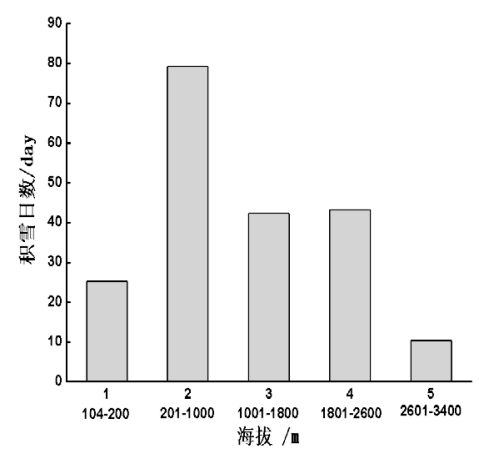

(b) 积雪日数分布

图 4 内蒙古地区 DEM 图和积雪日数分布 
部分区域, 兴安盟, 通辽市, 赤峰市和中 部锡林郭勒盟东北部, 这些地区正是受蒙 古高原和西伯利亚冷空气影响最深的地 区, 东亚与太平洋之间水汽输送的必经之 地。因为内蒙古西部海拔较高, 且积雪日 数较少, 因此并没有呈现明显的陡坎效 应。

\subsection{2 内蒙古积雪空间变化趋势}

由图 5(a)可知, 内蒙古地区积雪日数的 年际倾向率维持在-1.31 3.13 天/年之间, 其 中绝大部分的积雪日数倾向变化率在 $0 \sim 0.8$ 天/年的范围内, 占研究区的 $63 \%$ 。 $-1.31 \sim 0$ 天/年之间的占 $15.3 \%$, 是研究区唯一呈减 少趋势的区间, 主要分布在呼伦贝尔高原 和大兴安岭, 锡林郭勒盟的东北部和东南 部以及西部阿拉善盟的黑河水流域; 0.8 1.6 天/年之间的积雪日数变化倾向率分 布在呼和浩特市, 鄂尔多斯市, 包头市和 乌兰察布市, 占 $17.1 \%$ 。积雪日数倾向率在 $0.16 \sim 3.13$ 天/年的占 $4.6 \%$, 仅分布在呼伦贝 尔市的满洲里-新巴尔虎右旗和赤峰市。

逐像元分析积雪日数的显著性变化趋 势表明（图 5(b)）, 内蒙古地区呈增加趋势 的像元占 $84.7 \%$, 减少趋势像元的占 $15.3 \%$, 呈增加趋势的像元远高于减少趋 势, 其变化趋势与年际倾向率趋同。积雪 日数呈显著增长趋势的像元占 $26.4 \%$, 主要 分布在内蒙古中西部地区。呈不显著增长 趋势的像元占的 $58.3 \%$ 。呈不显著减少趋势 的像元最少, 仅占 $15.3 \%$ 。

\section{3 内蒙古积雪日数对气候的响应分析}

\subsection{1 积雪日数与气候统计分析}

由表 2 可知, 积雪日数与降水呈显著 正相关, 降水越多, 积雪日数就越长; 积 雪日数与气温显著负相关, 气温越高, 积 雪日数越短。

表 2 积雪日数与气候因子统计分析结果 Table.2 Statistical analysis result of snow days with climate factors

\begin{tabular}{ccc}
\multicolumn{3}{c}{ climate factors } \\
\hline 统计项 & 降水 & 气温 \\
\hline 积雪日数 & $0.452^{*}$ & $-0.768^{* *}$ \\
\hline **表示通过 0.01 的显著性检验 &
\end{tabular}

\subsection{2 积雪日数与气候的相关性分析}

由 1979 2014 年内蒙古 47 个气站点的 平均积雪日数, 分析积雪日数显著性水 平, 分析空间相关性结果, 可以得到: $83.3 \%$ 的站台积雪日数与降雨呈正相关。显 著区分布在内蒙古的东部和中部。93.7\%的 站台积雪日数与气温呈负相关, 呈显著相 关的站台数占 $45.8 \%$, 主要分布在内蒙古中 部和东部。

\section{4. 结论}

(1) 1979 2014 年内蒙古地区积雪日 数呈显著增长趋势 $(\mathrm{P}<0.05), 1996$ 年后积 雪日数表现为明显上升趋势。2000 年以 后, 积雪日数的波动较小; 内蒙古积雪日 数的突变年份是 2001 年。积雪日数偏多和 偏少年份也发生在 21 世纪后, 其中 2002 年

(第 28 天) 和 2001 年（第 22 天）年分别 是 35 年来积雪日数偏多和偏少的最大值。

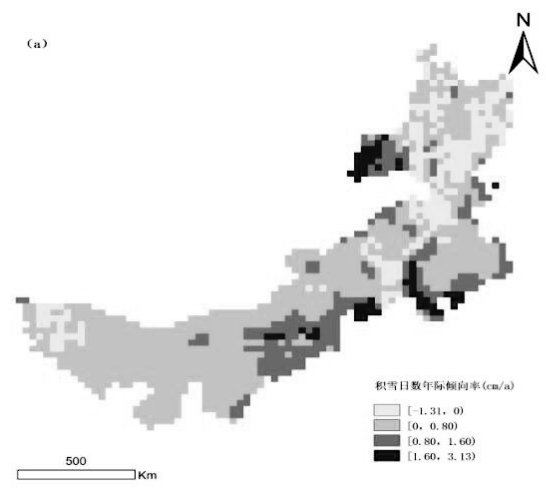

(a) 积雪日数变化趋势图

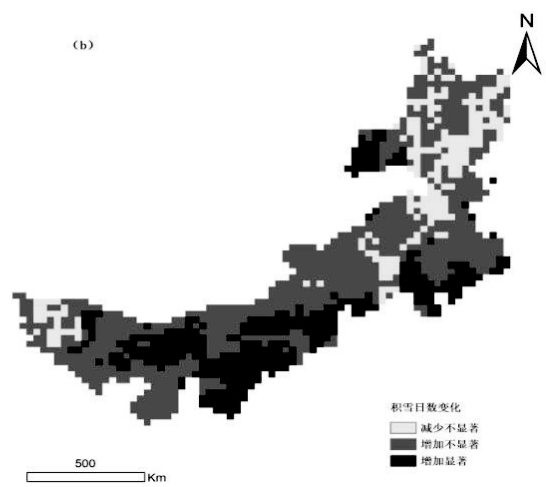

(b) 积雪日数空间分布显著性水平图

图 $51979^{\sim} 2014$ 年内蒙古积雪变化趋势和空间分布显著性水平图 
(2) 受地形和水分的影响, 内蒙古积 雪日数高值均分布在东北部的呼伦贝尔高 原和大兴安岭, 锡林郭勒东北部地区和锡 林郭勒东部与赤峰市西部的交接地带。低 值区主要分布在西部盟市, 包头市-巴彦淖 尔市-鄂尔多斯市-阿拉善盟一线。201 1000 米的海拔积雪日数均最高; 积雪日数倾向 变化率在 $0 \sim 0.8$ 天/年的范围内, 占研究区 的 $63 \%$; 积雪日数增加趋势的像元占 $84.7 \%$, 有减少趋势像元的仅占 $15.3 \%$ 。

(3) 积雪日数与降水、气温存在明显 的统计和空间相关关系, 积雪日数均与降 水呈正相关, 而与气温呈负相关。多元回 归分析模拟积雪日数的模拟值和实测值复 相关系数达到 0.825 , 且均通过 0.01 的显著 性检验。

\section{5. 讨论}

由于研究积雪的方法、获取的数据资 料及时空的差异, 得到积雪日数的时空变 化特征差异明显。内蒙古积雪的滞留天数 不仅受到气温的主要影响, 也受到地形 (海拔、坡向) 的影响, 此外, 受降水显 著影响的台站主要分布在内蒙古的东部和 中部。前人研究表明, 积雪日数受季节支 配的分布很显著, 且主要受到降水和气温 的影响 ${ }^{[17-18]}$, 而本文通过研究得到, 内蒙古 地区积雪日数与气温相关性较降雨更强; 与气温相关性最强表明, 气温的上升是引 起内蒙古积雪日数减少的主要原因。在充 分考虑内蒙古地形因素及其气候特征的情 况下, 如何提高积雪参数的分辨率来分析 其时空变化特征及其与驱动因子的关系, 还有待进一步的研究。

\section{Acknowledgements}

This study was supported by the Innovation team of disaster prevention and mitigation of grassland non biological disasters in Chinese Academy of Agricultural Sciences (CAASASTIP-IGR 2016-0406), the Natural Science Foundation of Inner Mongolia (No.2016MS 0409), Inner Mongolia science and technology project (201502095), and (201702116). Corresponding author: Sa Chula, Email : sachulan@126.com.

\section{致谢}

本研究得到了中国农业科学院草原非生物 灾害防灾减灾创新团队项目 (CAASASTIP-IGR 2016-0406), 内蒙古自然科学基 金项目(2016MS0409), 内蒙古科技计划项 目 (201502095) 和 (201702116) 的资助。

\section{参考文献}

[1] 王春学,李栋梁.中国近 50a 积雪日数与 最大积雪深度的时空变化规律. 冰川冻 土,2012,02:247-256. 谢平,邹传伟,互联 网金融模式研究, 中国人民大学出版社, 北京,2014.

[2] 唐小萍,闵小利, 尼玛吉, 路红亚. 西藏高 原近 40 年积雪日数变化特征分析. 地 理学报,2012,07:951-959.

[3] 李小兰,张飞民,王澄海.中国地区地面观 测积雪深度和遥感雪深资料的对比分 析.冰川冻土,2012, 04:755-764.

[4] 李培基,米德生.中国积雪的分布.冰川冻 土, 1983, 04:9-18.

[5] 韦志刚, 黄荣辉, 陈文, 董文杰.青藏高原 地面站积雪的空间分布和年代际变化 特征.大气科学,2002, 04:496-508.

[6] 刘俊峰,陈仁升.基于 MODIS 双卫星积 雪遥感数据的积雪日数空间分布研究 冰川冻土,2011, 03:504-511.

[7] 刘俊峰,陈仁升.东北一内蒙古地区基于 MODIS 单、双卫星积雪数据及常规积 雪观测结合的积雪日数研究. 遥感技术 与应用,2011,04:450-456.

[8]萨楚拉,刘桂香,包刚,包玉海, 王牧兰. 内 蒙古积雪面积时空变化及其对气候响 应. 干旱区资源与环境,2013,02:137-142。

[9] 田柳茜, 李卫忠,张尧,田立军,朱求安, 彭 长辉,陈槐. 青藏高原 1979-2007 年间 的积雪变化. 生态学报,2014,20:59745983.

[10] 曾群柱,雍世鹏, 顾钟炜.中国雪灾的分类 分级和危险度评价方法的研究. 北京: 中 国科技出版社, 1993 .

[11] 李培基. 中国西部积雪变化特征. 地理 学报,1993,06:505-515. 
[12] 冯学智,鲁安新,曾群柱. 中国主要牧区 雪灾遥感监测评估模型研究. 遥感学 报,1997,02:129-134.

[13] 萨楚拉. 内蒙古草原牧区雪灾监测与风 险评价研究.中国农业科学院,2015.

[14] Yi Z, Liu G, Yu F. The combustible materials remote sensing ration calculation and fire risk dynamic. Journal of Risk Analysis and Crisis Response, 2011, 1(1):65-74.

[15] 车涛, 李新. 利用被动微波遥感数据反演 我国积雪深度及其精度评价. 遥感技术 与应用,2004,05:301-306.

[16] Mohammat A, Wang X, Xu X, et al. Drought and spring cooling induced recent decrease in vegetation growth in Inner Asia. Agricultural and Forest Meteorology, 2013, 178-179(0): 21-30.

[17] 牛涛,刘洪利,宋燕,陈隆勋.青藏高原气 候由暖干到暖湿时期的年代际变化特 征研究.应用气象学报,2005, 06:763-771.

[18] 黄一民,章新平. 青藏高原四季降水变化 特征分析。长江流域资源与环 境,2007,04:537-542. 